\title{
Project Net Present Value estimation under uncertainty
}

\author{
Helena Gaspars-Wieloch ${ }^{1}$
}

\begin{abstract}
The paper contains a description of a possible modification of the original Net Present Value which allows one to evaluate projects under uncertainty with unknown probabilities (understood mainly as frequencies). Cash flows are usually uncertain since both incomes and expenditure related to the project concern the future. Additionally, probabilities of particular scenarios may be unknown due to many factors (e.g. the diversity of definitions for probability, lack of historical data, lack of sufficient knowledge about possible states of nature). The novel approach is based on a hybrid of Hurwicz and Bayes decision rules and is supported by a sensitivity analysis. The new method applies scenario planning and takes into account the decision maker's attitude towards a given decision problem (measured by coefficients of pessimism and optimism). The procedure can be used even in the case of asymmetric distributions of net cash flows at particular periods since it considers the frequency of each value. The modification of the Net Present Value may support any uncertain multi-period economic decision.
\end{abstract}

Keywords Project Net Present Value - Decision maker's nature · Uncertainty · Unknown probabilities (frequencies) · Decision making · Sensitivity analysis

\section{Introduction}

Projects may be evaluated and compared according to many statistic and dynamic methods of investment profitability assessment. One of them is the Net Present Value

\footnotetext{
$凶$ Helena Gaspars-Wieloch helena.gaspars@ue.poznan.pl

1 Department of Operations Research, Poznań University of Economics and Business, Al. Niepodległości 10, 61-875 Poznan, Poland
} 
(NPV), which was formalized and popularized by Fisher (1907). This measure is computed on the basis of all foreseen and discounted revenues and costs over the lifetime of the project. The traditional version of NPV treats future cash flows as certain (deterministic) values. Nevertheless, many contributions devoted to the NPV estimation are based on the assumption that those data are uncertain, which is totally justifiable since both incomes and expenditure related to the project concern the future (except for the cash flow at moment 0 ). There are several different methods designed for taking uncertainty in such calculations into account, for instance: (1) to increase the discount rate, (2) to apply sensitivity analysis, (3) to compare pessimistic and optimistic cash flows or, (4) to estimate the expected cash flows by means of scenario planning and the probability distribution.

Note that the last procedure may be applied on condition that the decision maker knows or is able to estimate the likelihood of particular scenarios (states of nature, events). Meanwhile, it is sometimes quite complicated to compute probabilities due to the existence of many discrepant definitions of probability (Carnap 1950; Frechet 1938; Hau et al. 2009; Knight 1921; Kolmogorov 1933; Piegat 2010; Popper 1959; van Lambalgen 1996; von Mises 1949, 1957), the lack of historical data in the case of totally new decisions and events (Guo 2011; Guo and Ma 2014; Gaspars-Wieloch 2015c, d, 2016a, b, 2017a, b), the lack of sufficient knowledge about particular states or the fact that the set of possible scenarios forecasted by experts in the scenario planning stage does not satisfy the probability axioms - the sum of state probabilities should be equal to 1 , the whole sample space must be precisely defined (see, Kolmogorov 1933). Furthermore, Finetti (1975) argues that objective probabilities do not exist: "No matter how much information you have, there is no scientific method to assign a probability to an event", there are only subjective probabilities-different for particular decision makers. However, according to Caplan (2001), people may be even unable to declare subjective probabilities - they just implicitly set probabilities when acting. Additionally, according to von Mises (1949), the theory of probability can never lead to a definite statement concerning a single event - the probability of a single event cannot be presented numerically. Roszkowska and Wachowicz (2015) also point out that people prefer ordinal measures to cardinal ones.

Despite the fact that the probability, in some circumstances, may be difficult to estimate, supporters of the theory of economics stress that some probability-like quantities can be often estimated and applied. Hence, in many cases, except for the aleatory uncertainty which is not reducible due to its random nature (Tannert et al. 2007; Zio and Pedroni 2013), uncertainty may be measured and quantified somehow (Piasecki 2016). Therefore, we would like to propose a new approach which can be used for project Net Present Value estimation under uncertainty with unknown objective probabilities. The procedure described in the paper will allow the decision maker (DM) to use scenario planning and to take into account his or her risk aversion measured by coefficients of optimism and pessimism. We assume that the novel procedure is designed for the selection of projects performed only once (see one-shot decisions, Gaspars-Wieloch 2015a, 2016a, b, 2017a, b, c; Kofler and Zweifel 1993), since the choice of a project from the same set of potential projects in the future requires re-scenario planning and a new declaration of the level of optimism. 
The paper is organized as follows. Section 2 deals with the main features of the traditionally understood NPV method. Section 3 concerns the NPV technique with uncertain parameters. Section 4 describes the problem in the context of uncertainty with unknown frequencies. Section 5 presents a decision rule that may be used as a tool in evaluating NPV under uncertainty. Section 6 provides a case study. Conclusions are gathered in the last part.

\section{Net Present Value}

The Net Present Value or Net Present Worth (Lin and Nagalingam 2000; Berk et al. 2015 ) is defined as the sum of the present values of incoming (benefits) and outgoing (costs) cash flows over a period of time. NPV can be described as the difference between the sums of discounted cash inflows and cash outflows. According to the investment profitability assessment method based on NPV, a cash flow today is more valuable than an identical cash flow in the future because a present flow can be invested immediately and begin earning returns, while a future flow cannot (Berk et al. 2015).

NPV is a useful tool to determine whether a project will result in a net profit (NPV is positive, hence the investment would add value to the firm and the project may be accepted) or a loss (NPV is negative, hence the investment would subtract value from the firm and the project should be rejected). In the financial theory, if there is a choice between two mutually exclusive alternatives, the one yielding the higher NPV should be selected (https://en.wikibooks.org/wiki/Principles_of_Finance). NPV plays a central role in discounted cash flow (DCF) analysis and is a standard method for using the time value of money to appraise long-term projects (https://en.wikipedia. org/wiki/Net_present_value). It is widely applied throughout economics, finance and accounting (Balen et al. 1988; Naim et al. 2007). The NPV of a sequence of cash flows takes the cash flows and a discount rate as input, and outputs a price. ${ }^{1}$ NPV may be calculated by means of one of the following time-discrete equations:

$$
\begin{aligned}
& N P V=\sum_{t=0}^{n} \frac{N C F_{t}}{(1+r)^{t}} \\
& N P V=\sum_{t=0}^{n} \frac{C I_{t}}{(1+r)^{t}}-\sum_{t=0}^{n} \frac{C O_{t}}{(1+r)^{t}} \\
& N P V=\sum_{t=0}^{n} \frac{C I_{t}}{(1+r)^{t}}-C O_{0}
\end{aligned}
$$

\footnotetext{
1 The converse process in DCF analysis consists in taking a sequence of cash flows and a price as input and inferring a discount rate as output, see Internal Rate Return (IRR). IRR or other efficiency measures are used as a complement to NPV because the latter tool does not provide an overall picture of the gain or loss of executing a certain project. Meanwhile IRR allows one to see a percentage gain relative to the investments in the project (https://en.wikipedia.org/wiki/Discounted_cash_flow, https://www.boundless. com/finance/).
} 
where $n$-number of periods; $N C F_{t}$-net cash flow at moment $t ; r$-discount rate (the rate of return that could be earned from an investment in the financial markets with similar risk); $C I_{t}$ - cash inflow at moment $t ; C O_{t}$-cash outflow at moment $t$.

Equation (1) allows one to compute the sum of the discounted net cash flows. Equation (2) enables one to set the difference between the present value of benefits and the present value of costs. Formula (3) is a simplified version of Eq. (2) and it may be applied to situations with only one expense at the beginning of the project. The construction of NPV is based on a simplifying assumption that the net cash received or paid occurs in a single transaction on the last day of each period (https://www. boundless.com/finance).

NPV can also be written in a continuous variation (Buser 1986; Grubbström 1967), but in this paper we investigate only the discrete case. The original version of NPV applies a constant discount rate, which is suitable for short-term projects. The use of a variable discount rate is desirable when appreciating long-term investments (Fabozzi and Fong 1994; Piasecki and Ronka-Chmielowiec 2011). Here, we focus on constant discount rates. Due to the fact that the decision maker can reinvest particular cash flows, the true NPV may be higher. Therefore, the Modified Net Present Value has been proposed (Chandra 2009; Filho et al. 2012; McClure and Girma 2004). In this contribution we concentrate on NPV, but the reinvestment factor can be easily introduced.

\section{Net Present Value under uncertainty}

Owing to the fact that, in most of cases, cash flows cannot be estimated in a very precise way since they are related to future periods, the exploration of NPV computations under uncertainty is justifiable. Due to the necessity to solve decision problems with uncertain parameters, a variety of theories have been developed, e.g. the probability theory (Kolmogorov 1933), the imprecise (interval) probability (Walley 1991), the evidence theory (Shafer 1976; Sentz and Ferson 2002), the possibility theory (Zadeh 1978; Dubois and Prade 2001) and the uncertainty theory (Liu 2007, 2009). It is worth emphasizing that there is no unanimity in defining the notion of uncertainty (Gaspars-Wieloch 2017a). According to the theory of decision the DM may choose the appropriate alternative (decision, strategy, variant):

- under certainty (DMC) where parameters are deterministic,

- under risk (DMR) where possible scenarios and their likelihood are known,

- with partial information (DMPI) where possible states of nature are known, but their probability is known incompletely: the DM only knows the order of scenarios or the intervals with possible probabilities for each scenario,

- under complete uncertainty (DMCU) where the scenarios are known, but the probability of their occurrence is not, or

- under total ignorance (DMTI) where the DM is not able to define possible events.

Note that DMCU may also occur when the DM does not want to make use of the estimated probability distribution (Trzaskalik 2008). Comments concerning particular decision making circumstances can be found, for instance, in Chronopoulos et al. (2011), Groenewald and Pretorius (2011), Guo (2011), Kaplan and Barish (1967), 
Knight (1921), Perez et al. (2015), Render et al. (2006), Sikora (2008), Waters (2011) and Weber (1997). Uncertainty and risk were formally integrated in the economic theory by von Neumann and Morgenstern (1994). Supporters of the theory of economics state that uncertainty involves all the situations with non-deterministic parameters (known, unknown or incompletely known probability distribution, lack of information about possible scenarios), while risk is related to the possibility that some bad or other than predicted circumstances will happen (Aven 2016; Dominiak 2009; Dubois and Prade 2012; Fishburn 1984; Gaspars-Wieloch 2016b; Guney and Newell 2015; Ogryczak and Sliwinski 2009; Waters 2011). Nevertheless, as it was mentioned in the introduction, within the theory of economics, even if the probability is not known, some probability-like quantities can be often estimated and applied. Apart from the two approaches described above, The Austrian Economic School is worth mentioning. It treats uncertainty as decision theorists do, i.e. as a situation where the likelihood is not known. Additionally, it is assumed that the mathematical probability of the occurrence of a given scenario is not known since probabilities concern only repetitive events, meanwhile in the majority of real problems the DM deals with non-repetitive events. According to von Mises (1949), the theory of probability can never lead to a definite statement concerning a single event - the probability of a single event cannot be presented numerically. The Austrian Economists state that uncertainty is not caused by the randomness of events, as main-stream economists think, but by many factors and only some of them are known in the DM process (Gaspars-Wieloch 2017a). Note that scientists distinguish two main types of uncertainty: the epistemic/epistemological (reducible) uncertainty — due to the lack of knowledge (it can be reduced or eliminated after collecting information), and the aleatory/aleatoric (random) uncertainty-due to the inherent variability in a physical phenomenon (it cannot be reduced even after conducting $n$ experiments) (Zio and Pedroni 2013).

In this paper we consider both the epistemic and aleatory uncertainty, which leads us to a conclusion that the likelihood of the occurrence of particular states of nature cannot be estimated in an accurate way. Additionally, owing to the fact that the contribution concerns one-shot decisions only (the selected project is performed only once, i.e. only one state of nature has the chance to occur within a given period), we refer in a sense to the Austrian approach where the probability understood as frequency cannot be computed for a single event. The theory of economics is also partially applied in this research since unknown probabilities are going to be replaced by some probability-like quantities.

Uncertainty in NPV has been already taken into account in many ways. For instance, one can increase the discount rate (Method I). Nevertheless, some researchers state that it is not a reasonable approximation since the increased discount rate reduces the impact of potential losses below their true financial cost. Actually, the increased discount rate reduces the impact of potential losses, but the use of a higher discount rate signifies that the DM intends to earn more and that he/she is more willing to risk (lose) his/her money - usually more profitable investments are riskier. On the other hand, if the DM applies a lower discount rate, that means that he/she intends to earn less and that he/she does not accept the possibility of the occurrence of significant losses-usually less profitable investments are less risky. Thus, in our opinion, the 
level of the discount rate reflects the DM's nature (risk-prone behavior, risk-averse behavior), not the degree of uncertainty.

Another way consists in compounding the risk premium with the risk free rate (Method II). However, as a result, future cash flows are discounted by both rates, which entails an extremely low NPV.

The sensitivity analysis may be also applied to NPV (Method III), which enables one to check how NPV varies depending on the level of particular cash flows. Furthermore, it gives the possibility to set the interval for a cash flow at a given moment, within which NPV remains positive or higher than the NPV of another project.

When the DM knows possible scenarios at particular moments, it is recommended to refer to scenario planning (Pomerol 2001; Van der Heijden 1996). One can, for example, compare pessimistic and optimistic cash flows (Method IV), and, if the likelihood of each state of nature is estimated, the expected NPV may be calculated. The latter method (r-NPV: risk-adjusted Net Present Value) consists of the following steps: (1) computing the expected net cash flow $E\left(N C F_{t}\right)$ and standard deviations $\left(S D_{t}\right)$ at particular moments, (2) calculating the expected NPV, i.e. $E(N P V)$, and the mean standard deviation $(M S D)$ for the project, (3) computing the coefficient of variation $C V$ (the quotient of $M S D$ and $E(N P V)$ ) - the lower $C V$ is, the less risky the project is (Method V).

When probabilities are not known, but the mean net cash flows $\left(M N C F_{t}\right)$, standard deviations $\left(S D_{t}\right)$ and correlations between sequences of cash flows from different periods $\left(\rho_{t, s}\right)$ are given, $M N C F_{t}$ values are treated as $E\left(N C F_{t}\right)$ and the whole standard deviation is computed on the basis of the partial standard deviations and the aforementioned correlations (Method VI).

The NPV estimation under uncertainty may be also supported by fuzzy numbers and interval arithmetic (Chiu and Park 1994; Gutiérrez 1989; Filho et al. 2012) (Method VII).

The above list of procedures designed for NPV calculation under uncertainty is not exhaustive, but allows one to be aware of the impressive variety of the existing approaches. In Sect. 4 we will concentrate on NPV in the context of scenario planning, risk aversion and uncertainty with unknown frequencies.

\section{Scenario planning, risk aversion and NPV under uncertainty}

Now, let us analyze the case of NPV estimation when the DM knows possible scenarios at particular moments and net cash flows connected with them, but the likelihood, mainly understood as frequency, is not known. Additionally, we assume that the DM is not able to define particular subjective probabilities exactly since his knowledge about future scenarios is not sufficient - the assessed projects are new. The result of the choice made under uncertainty depends on two factors: which decision (project, investment) is selected (internal factor) and which scenarios will occur in the future (external factor).

The NPV estimation under uncertainty with unknown probabilities may be presented with the aid of a cash flow matrix (Table 1) where $n$ is the number of projects $\left(I_{1}, I_{2}, \ldots, I_{j}, \ldots, I_{n}\right), T$ denotes the number of future periods $(1,2, \ldots, t, \ldots, T)$ 
Table 1 The uncertain cash flow matrix for a set of projects. Source: Prepared by the author

\begin{tabular}{llll}
\hline Periods $\backslash$ investments & $\mathrm{I}_{1}$ & $\mathrm{I}_{\mathrm{j}}$ & $\mathrm{I}_{\mathrm{n}}$ \\
\hline 0 & $\mathrm{NCF}_{0,1}$ & $\mathrm{NCF}_{0, \mathrm{j}}$ & $\mathrm{NCF}_{0, \mathrm{n}}$ \\
1 & $\mathrm{NCF}_{1,1}^{1}$ & $\mathrm{NCF}_{1, \mathrm{j}}^{1}$ & $\mathrm{NCF}_{1, \mathrm{n}}^{1}$ \\
& $\mathrm{NCF}_{1,1}^{\mathrm{k}(1,1)}$ & $\mathrm{NCF}_{1, \mathrm{j}}^{\mathrm{k}(1, \mathrm{j})}$ & $\mathrm{NCF}_{1, \mathrm{n}}^{\mathrm{k}(1, \mathrm{n})}$ \\
& $\mathrm{NCF}_{1,1}^{\mathrm{m}(1,1)}$ & $\mathrm{NCF}_{1, \mathrm{j}}^{\mathrm{m}(1, \mathrm{j})}$ & $\mathrm{NCF}_{1, \mathrm{n}}^{\mathrm{m}(1, \mathrm{n})}$ \\
$\mathrm{t}$ & $\mathrm{NCF}_{\mathrm{t}, 1}^{1}$ & $\mathrm{NCF}_{\mathrm{t}, \mathrm{j}}^{1}$ & $\mathrm{NCF}_{\mathrm{t}, \mathrm{n}}^{1}$ \\
& $\mathrm{NCF}_{\mathrm{t}, 1}^{\mathrm{k}(\mathrm{t}, 1)}$ & $\mathrm{NCF}_{\mathrm{t}, \mathrm{j}}^{\mathrm{k}(\mathrm{t}, \mathrm{j})}$ & $\mathrm{NCF}_{\mathrm{t}, \mathrm{n}}^{\mathrm{k}(\mathrm{t}, \mathrm{n})}$ \\
& $\mathrm{NCF}_{\mathrm{t}, 1}^{\mathrm{m}(\mathrm{t}, 1)}$ & $\mathrm{NCF}_{\mathrm{t}, \mathrm{j}}^{\mathrm{m}(\mathrm{t}, \mathrm{j})}$ & $\mathrm{NCF}_{\mathrm{t}, \mathrm{n}}^{\mathrm{m}(\mathrm{t}, \mathrm{n})}$ \\
& $\mathrm{NCF}_{\mathrm{T}, 1}^{1}$ & $\mathrm{NCF}_{\mathrm{T}, \mathrm{j}}^{1}$ & $\mathrm{NCF}_{\mathrm{T}, \mathrm{n}}^{1}$ \\
& $\mathrm{NCF}_{\mathrm{T}, 1}^{\mathrm{k}(\mathrm{T}, 1)}$ & $\mathrm{NCF}_{\mathrm{T}, \mathrm{j}}^{\mathrm{k}(\mathrm{T}, \mathrm{j})}$ & $\mathrm{NCF}_{\mathrm{T}, \mathrm{n}}^{\mathrm{k}(\mathrm{T}, \mathrm{n})}$ \\
& $\mathrm{NCF}_{\mathrm{T}, 1}^{\mathrm{m}(\mathrm{T}, 1)}$ & $\mathrm{NCF}_{\mathrm{T}, \mathrm{j}}^{\mathrm{m}(\mathrm{T}, \mathrm{j})}$ & $\mathrm{NCF}_{\mathrm{T}, \mathrm{n}}^{\mathrm{m}(\mathrm{T}, \mathrm{n})}$ \\
\hline
\end{tabular}

and $m(t, j)$ signifies the number of mutually exclusive scenarios (let us denote them by $\left.S_{(t, j)}^{1}, S_{(t, j)}^{2}, \ldots, S_{(t, j)}^{k(t, j)}, \ldots, S_{(t, j)}^{m(t, j)}\right)$ connected with period $t$ and investment $I_{j}$. Symbol $N C F_{t, j}^{k(t, j)}$ stands for the net cash flow related to period $t$, investment $I_{j}$ and scenario $S_{(t, j)}^{k(t, j)}$. Note that the number of states of nature for particular periods and investments may vary - the sets of states of nature are independent! Of course, if there is no cash flow at a given moment $t$ in the case of one of the considered projects, parameters $N C F_{t, j}^{k(t, j)}$ for that investment are equal to zero. The cash flow matrix may be generated by the decision maker (the first case) or by experts (the second case). In the second case, parameters are more objective, which is an advantage. In Table 1, scenario planning is applied only to future periods: $1, \ldots, t, \ldots, T$ since one can assume that the first cash flow $(t=0)$ constitutes a deterministic parameter.

Given such data, one could calculate the expected NPV on the basis of Method VI (see Sect. 3). Nevertheless, this time, we assume that the number of scenarios for a given period may be different for particular investments. Additionally, we will attempt to take into account the DM's nature measured by the coefficients of pessimism $(\alpha)$ and optimism $(\beta)$. These parameters belong to interval $[0,1]$ and satisfy the condition $\alpha+\beta=1 . \alpha(\beta)$ tends to 0 (1) for extreme optimists (risk-prone behavior) and is close to $1(0)$ for extreme pessimists (risk-averse behavior). Coefficients of pessimism and optimism have been already used in the decision making process, for instance in Hurwicz (1952) and Perez et al. (2015). In this contribution they will allow us to generate some probability-like quantities. Note that those quantities will not be directly estimated by the decision makers, but will be calculated on the basis of their level of optimism/pessimism. Hence, coefficients $\alpha$ and $\beta$ are the initial parameters and probability-like quantities constitute the secondary parameters.

There are numerous decision rules devoted to decision making under uncertainty (see, for example, Basili 2006; Basili et al. 2008; Basili and Chateauneuf 2011; Beauchene 2015; Chassein and Goerigk 2016; Ellsberg 2001; Etner et al. 2012; Gaspars-Wieloch 2012, 2013, 2014a, b, c, d, 2015a, b, c, d, e, 2016a, b, 2017a, b, c, d; 
Ghirardato et al. 2004; Gilboa 2009; Gilboa and Schmeidler 1989; Halpern and Leung 2014; Hayashi 2008; Hurwicz 1952; Ioan and Ioan 2011; Marinacci 2002; Nakamura1996; Perez et al. 2015; Piasecki 1990; Savage 1961; Schmeidler 1986; Tversky and Kahneman 1992; Wald 1950), but some of them are based on the probability calculus or do notconsider the DM's nature-thus, they cannot be applied to the aforementioned problem.

In Sect. 5 we are going to present the $\mathrm{H}+\mathrm{B}$ decision rule for NPVU (Net Present Value under uncertainty). The original version of that procedure, i.e. the $\mathrm{H}+\mathrm{B}$ rule (a hybrid of Hurwicz and Bayes rules), is described in Gaspars-Wieloch (2014a, 2015b, c, 2016 b). It is designed for decision making under uncertainty with unknown probabilities. Thanks to parameters $\alpha$ and $\beta$, the $\mathrm{H}+\mathrm{B}$ rule enables one to take into consideration the DM's attitude towards a given problem The procedure is devoted to searching optimal pure (not mixed) strategy and to solving one-shot decision problems (Guo 2011). A pure strategy, as opposed to a mixed strategy, allows the DM to select and perform only one accessible alternative (Gaspars-Wieloch 2015e). One-shot decision problems are connected with decisions performed only once.

Of course, one should wonder why we do not intend to apply the original Hurwicz decision rule, which also uses $\alpha$ and $\beta$ and usually leads to sensible results. The disadvantage of that approach is related to the following factor. In some cases the Hurwicz rule provides answers which are contradictory to the logic and do not reflect the decision maker's preferences. Such a phenomenon stems from the fact that the Hurwicz criterion takes extreme payoffs into consideration only-transitional values connected with a given decision are ignored. Additionally, the above rule does not examine the frequency of relatively high and low payoffs belonging to the set of all profits assigned to particular alternatives (see, Gaspars-Wieloch 2012, 2014a, c, 2016 b). In the $\mathrm{H}+\mathrm{B}$ rule, in contrast to the Hurwicz approach, all outcomes have an influence (though not the same) on the value of the final measure. Hence, the $\mathrm{H}+\mathrm{B}$ approach recommends logic rankings for both symmetric and asymmetric distributions of payoffs. And that is why it may be useful in the evaluation (choice) of investment projects on the basis of NPV under uncertainty. Note that the original H+B decision rule needs to be adjusted to that goal (i.e. NPV estimation) since, this time, payoffs connected with particular projects come from different periods.

\section{The H+B decision rule for NPV under uncertainty (NPVU)}

The suggested $\mathrm{H}+\mathrm{B}$ rule for NPVU may consist of the following steps:

1. Define $n$ (the number of projects) and generate the cash flow matrix for the whole set of projects, see Table 1 .

2. Determine $\alpha$ and $\beta$ for a given problem. If $\alpha \in[0,0.5)$, then $\alpha=\alpha_{o}, \beta=\beta_{o}\left(\alpha_{o}\right.$ and $\beta_{o}$ are the optimist's coefficients). If $\alpha \in(0.5,1]$, then $\alpha=\alpha_{p}, \beta=\beta_{p}\left(\alpha_{p}\right.$ and $\beta_{p}$ are the pessimist's coefficients).

3. Find a non-increasing sequence of net cash flows $S q_{t, j}^{=}\left(a_{t, j}^{1}, \ldots, a_{t, j}^{s}, \ldots, a_{t, j}^{m(t, j)}\right)$ for each project $I_{j}$ and for each period $t=1, \ldots, T$, where $a_{t, j}^{s} \geq a_{t, j}^{s+1}(s=$ 
$1, \ldots, m(t, j)-1), m(t, j)$-number of terms in the sequence, $s$-number of the term in the sequence.

4. Calculate, for each project and each period, index $h b_{t, j}\left(h b_{t, j}^{p}, h b_{t, j}^{o}\right.$ or $h b_{t, j}^{0.5}$ depending on parameter $\alpha$ ). If $\alpha \in(0.5,1]$, calculate $h b_{t, j}^{p}$ (index for pessimists) according to Eq. (4). If $\alpha \in[0,0.5)$, compute $h b_{t, j}^{o}$ (index for optimists) following formula (5). If $\alpha=0.5$, calculate $h b_{t, j}^{05}$ using Eq. (6), where $b_{t, j}$ denotes the Bayes criterion, i.e. the average of all net cash flows at a given period.

$$
\begin{aligned}
h b_{t, j}^{p} & =\frac{\alpha_{p} \cdot a_{t, j}^{m(t, j)}+\beta_{p} \cdot \sum_{s=1}^{m(t, j)-1} a_{t, j}^{s}}{\alpha_{p}+(m(t, j)-1) \cdot \beta_{p}} \\
h b_{t, j}^{o} & =\frac{\alpha_{o} \sum_{s=2}^{m(t, j)} a_{t, j}^{s}+\beta_{o} a_{t, j}^{1}}{(m(t, j)-1) \cdot \alpha_{o}+\beta_{o}} \\
h b_{t, j}^{0.5} & =h b_{t, j}^{p}=h b_{t, j}^{o}=b_{t, j}=\frac{1}{m(t, j)} \cdot \sum_{k(t, j)=1}^{m(t, j)} N C F_{t, j}^{k(t, j)}
\end{aligned}
$$

The denominators in Eqs. (4)-(5) are introduced so that the final value of particular indices belongs to interval $\left[a_{t, j}^{m(t, j)}, a_{t, j}^{1}\right]$.

If, for a given project, there is no net cash flow at period $t$, then $h b_{t, j}=0$. In the case of period $t=0, h b_{0, j}=N C F_{0, j}$.

5. Compute, for each project, $\alpha N P V_{j}$ (i.e. the Net Present Value considering the DM's nature) on the basis of formula (7).

$$
\alpha N P V_{j}=\sum_{t=0}^{T} \frac{h b_{t, j}}{(1+r)^{t}},
$$

where $r$ still denotes the discount rate, i.e. the rate of return that could be earned from an investment in the financial markets with similar risk.

6. Find project $I_{j}^{*}$ fulfilling condition (8). If only one project satisfies Eq. (8) and its $\alpha N P V_{j}$ value is positive, select that project. Otherwise, go to step 7.

$$
I_{j}^{*}=\underset{j}{\arg \max }\left(\alpha N P V_{j}\right)
$$

7. If one or more projects satisfy Eq. (8) and its (their) $\alpha N P V_{j}$ value is not positive, reject all projects or decrease the level of the discount rate, if it is justifiable, and go to step 5. Otherwise, go to step 8.

8. If more than one project satisfies Eq. (8) and their $\alpha N P V_{j}$ value is positive, calculate the mean standard deviation ( $n M S D)$ only for projects $I_{j}^{*}$ following condition (9). Pessimists should choose the project with the lowest mean standard deviation. Moderate DMs and optimists may select a project $I_{j}^{*}$ with more diffused cash flows (i.e. with a higher $M S D$ ). 


$$
\overline{M S D_{j}}=\frac{1}{T} \sqrt{\sum_{t=1}^{T}\left(\frac{1}{m(t, j)} \sum_{s=1}^{m(t, j)}\left(a_{i, j}^{s}-\overline{a_{t, j}}\right)^{2}\right)}
$$

In the last part of Sect. 5 we would like to explain equations given in step 4 of the algorithm presented above in detail.

The assignment of such parameters ( $\alpha$ and $\beta$ ) to particular elements of nonincreasing sequences in Eqs. (4)-(5), depending on the level of pessimism/optimism, is substantiated in Gaspars-Wieloch (2014a, 2015b, c, 2016b) where the author concludes that, as opposed to the Hurwicz rule, the index value should depend on all payoffs, not only on the extreme ones. Hence, parameters $\alpha$ and $\beta$ have to be assigned to all of them, not only to the best and to the worst ones, and such a feature is typical of Bayes rule. Owing to the fact that an extreme optimist rather focuses on the highest payoff, an extreme pessimist focuses rather on the lowest payoff and a moderate DM mainly analyzes intermediate profits, the assignment of coefficients is supposed to be different, depending on the DM's nature. Therefore, in the author's opinion, in the case of optimists, the high coefficient of optimism should be assigned to $a_{j, \max }$ and the small coefficient of pessimism should be assigned to the remaining gains since optimists expect the occurrence of the best scenario, so it should have the biggest weight. In the case of pessimists, the high $\alpha$ ought to be multiplied by $a_{j, \min }$ and the small $\beta$ ought to be multiplied by the other profits. In the case of moderate DMs with parameters $\alpha=\beta=0.5$, it does not matter which equation (4 or 5) will be applied, since the use of both of them boils down to equal weights for each gain. The approach described above allows one to take into consideration the frequency of extreme, or nearly extreme, values. Of course, we may ask why parameters $\alpha$ and $\beta$ should be assigned to particular payoffs in that way. The answer is that if we assign them in an inverse way, i.e. for optimists the low $\alpha$ to $a_{j, \min }$ and the high $\beta$ to the other profits, and for pessimists the low $\beta$ to $a_{j, \max }$ and the high $\alpha$ to the remaining gains, we will assume that the pessimist expects, apart from the lowest profit, the occurrence of quite high ones (without the highest one) and that the optimist, apart from the highest profit, expects the occurrence of quite low ones (without the lowest one), which is illogical. The idea of the hybrid presented in Gaspars-Wieloch (2014a) is to recommend for a strong pessimist an alternative with a relatively high payoff $a_{j, \min }$ or with quite frequent payoffs (almost) equal to $a_{j, \text { max }}$. On the other hand, that rule suggests for a strong optimist an alternative with the highest, or almost the highest, payoff $a_{j, \max }$, but its highest payoffs do not have to be frequent. Thus, the H+B rule for NPVU recommends for a pessimist a project with relatively high net cash flows $a_{t, j}^{m(t, j)}$ or with many net cash flows close to $a_{t, j}^{1}$. For an optimist, this procedure suggests an investment with the highest net cash flows $a_{t, j}^{1}$, but its highest flows do not have to be frequent (Gaspars-Wieloch 2016b). When analyzing the levels of the aforementioned coefficients assigned to particular net cash flows, we may also question the use of merely two values instead of gradually increasing/decreasing parameters for consecutive payoffs connected with a given project and a given period. Let's discuss the optimist's case (the conclusions for the pessimist's case are drawn by analogy). Why, for instance, is 
$\beta_{o}$ assigned only to $a_{j, \max }$ ? An optimist might expect that higher cash flows are more likely to occur, but not necessarily think that only the single highest cash flow has much higher chance to occur compared to the rest. The explanation is as follows. If one is an extreme optimist, he or she counts only on the highest payoff and then $\beta_{o}=1$ (for the highest cash flow) and $\alpha_{o}=0$ (for other cash flows), just like in the case of the Hurwicz rule. If one becomes a moderate optimist, one is not so sure whether the highest payoff will occur. Hence, $\beta_{o}$ decreases and $\alpha_{o}$ increases: $0.5<\beta_{o}<1$ (for the highest cash flow) and $0<\alpha_{o}<0.5$ (for other cash flows). The less optimistic one is, the less likely the best payoff is and the more likely other payoffs are. Gradually increasing or decreasing parameters would be possible, but note that if so, the sequences of weights would not be the same for each investment in a given period. They would be different for particular projects since they would depend on the level of all intermediate payoffs. The idea of using diverse sequences of weights for each project would be perhaps more comprehensible. Nevertheless, there are three reasons for which the author applies two values only: $\beta_{o}$ for the best cash flow and $\alpha_{o}$ for the remaining ones. Firstly, the use of $\alpha_{o}$ for intermediate payoffs provides the opportunity to take them into consideration and to include information about the frequency of extreme values in the final index (as opposed to the Hurwicz rule). Secondly, the use of increasing/decreasing parameters would not be appropriate for extreme decision makers with the coefficient of optimism equal to 1 since payoffs approximating the highest one would have too great importance: if the DM is an extreme optimist, only the best cash flow is vital for him - others are unimportant. Thirdly, the use of various parameters would entail additional, redundant computations as the change of weights for intermediate cash flows does not affect the rankings significantly.

It is worth emphasizing that in the procedure proposed in Gaspars-Wieloch (2014a) the index value depends on the number of states of nature, which is not the case of Hurwicz rule. For pessimists, when the number of scenarios increases, the importance of payoff $a_{j, \min }$ in the index decreases and the significance of the remaining profits increases. On the other hand, for optimists, the importance of payoff $a_{j, \text { max }}$ decreases and the significance of the remaining profits increases. Hence, again, we can observe the impact of Bayes rule in the analyzed hybrid, because the chance of the occurrence of a given event decreases along with the growth in the number of states of nature (Gaspars-Wieloch 2016b).

Note that the sensitivity analysis may effectively support the H+B rule for NPVU. If possible, it is recommended to generate project rankings for different values of the discount rate and the coefficient of optimism. Given such a specification, the decision maker can make his or her final decision more consciously (see Method III in Sect. 3).

As it can be noticed, the H+B rule for NPVU contains an additional step (in comparison to the original $\mathrm{H}+\mathrm{B}$ ), i.e. the computation of the mean standard deviation. That element is characteristic of Method V (Sect. 3), but this time, we apply that measure only to the multiple solutions case.

In the described algorithm (H+B for NPVU) coefficients of pessimism/optimism are supposed to be constant, i.e. the same for each period. However, the DM may state that each period could be influenced by different factors, negative and positive, and that the level of those parameters should vary. The procedure may be easily extended and provides an opportunity to declare different values for $\alpha$ and $\beta$, i.e. $\alpha_{1}, \alpha_{2}, \ldots, \alpha_{t}$, 
Table 2 The cash flow matrix for a set of projects

(Example)_in thousand dollars. Source: prepared by the author

\begin{tabular}{lrrr}
\hline Periods $\backslash$ investments & $\mathrm{I}_{1}$ & $\mathrm{I}_{2}$ & \multicolumn{1}{c}{$\mathrm{I}_{3}$} \\
\hline 0 & -50 & -0 & -120 \\
1 & -30 & 0 & -50 \\
& -20 & & -60 \\
& -40 & & -80 \\
& 0 & & \\
2 & 100 & 200 & 0 \\
& 130 & 170 & \\
& 150 & 160 & \\
& 140 & 80 & 300 \\
3 & 200 & 0 & 250 \\
& 50 & 50 & 500 \\
& 0 & 70 & \\
\hline
\end{tabular}

$\ldots, \alpha_{T}$ and $\beta_{1}, \beta_{2}, \ldots, \beta_{t}, \ldots, \beta_{T}$ (step 2) and to apply different formulas (Eqs. 4, 5 or 6 , step 4) for each period depending on the level of the aforementioned coefficients. Note that all coefficients must be given before the choice of the project.

\section{Case study}

In this section we are going to solve a simple example presented in Table 2 by means of the $\mathrm{H}+\mathrm{B}$ rule for NPVU.

We assume that the DM is a pessimist:

1. $n=3$, the cash flow matrix is given in Table 2 .

2. $\alpha=\alpha_{p}=0.7, \beta=\beta_{p}=0.3$ (here the DM declares constant parameters for each period).

3. The non-increasing sequences are as follows:

- for $\mathrm{I}_{1}: S q_{1,1}=(0,-20,-30,-40), S q_{2,1}=(150,140,130,100), S q_{3,1}=$ $(200,50,0)$,

- for $\mathrm{I}_{2}: S q_{2,2}=(200,170,160,80), S q_{3,2}=(150,70,50,0)$,

- for $\mathrm{I}_{3}: S q_{1,3}=(-50,-60,-80), S q_{3,3}=(500,300,250)$.

4. Indices $h b_{t, j}^{p}$ are computed in the following way (all the indices are presented in Table 3):

$$
\begin{aligned}
h b_{1,1}^{p} & =\frac{0.7 \cdot(-40)+0.3 \cdot(-30-20+0)}{0.7+3 \cdot 0.3}=-26.875 \\
h b_{2,1}^{p} & =\frac{0.7 \cdot 100+0.3 \cdot(150+140+130)}{0.7+3 \cdot 0.3}=122.5 \\
h b_{3,1}^{p} & =\frac{0.7 \cdot 0+0.3 \cdot(200+50)}{0.7+2 \cdot 0.3}=57.692 .
\end{aligned}
$$


Table 3 Indices $h b_{t, j}^{p}$ (in thousand dollars). Source: prepared by the author

\begin{tabular}{lrrr}
\hline Periods $\backslash$ investments & \multicolumn{1}{c}{$\mathrm{I}_{1}$} & \multicolumn{1}{c}{$\mathrm{I}_{2}$} & \multicolumn{1}{c}{$\mathrm{I}_{3}$} \\
\hline 0 & -50.000 & -90.000 & -120.000 \\
1 & -26.875 & 0.000 & -68.462 \\
2 & 122.500 & 134.375 & 0.000 \\
3 & 57.692 & 50.625 & 334.615 \\
\hline
\end{tabular}

Table 4 Measures $\alpha N P V_{j}$ (in thousand dollars) for different discount rates $(\alpha=0.7)$.

Source: prepared by the author

\begin{tabular}{lllll} 
Table 4 Measures $\alpha N P V_{j}$ (in \\
thousand dollars) for different \\
\cline { 2 - 5 } $\begin{array}{l}\text { discount rates }(\alpha=0.7) . \\
\text { Source: prepared by the author }\end{array}$ & 0.15 & $\mathrm{I}_{1}$ & $\mathrm{I}_{2}$ & $\mathrm{I}_{3}$ \\
\cline { 2 - 5 } & 0.14 & 57.19 & 44.89 & 40.48 \\
& 0.13 & 59.63 & 47.57 & 45.80 \\
& 0.12 & 62.14 & 50.32 & 51.32 \\
& 0.11 & 64.72 & 53.16 & 57.05 \\
& 0.10 & 67.40 & 56.08 & 62.99 \\
& 0.09 & 70.15 & 59.09 & 69.16 \\
& 0.08 & $\mathbf{7 3 . 0 0}$ & $\mathbf{6 2 . 1 9}$ & $\mathbf{7 5 . 5 8}$ \\
& 0.07 & 75.94 & 65.39 & 82.24 \\
The values for the discount rate & 0.06 & 78.97 & 68.69 & 89.16 \\
analyzed $(r=9 \%)$ are marked & 0.05 & 82.11 & 72.10 & 96.36 \\
in bold & & 85.35 & 75.61 & 103.85 \\
\cline { 2 - 5 }
\end{tabular}

The values for the discount rate analyzed $(r=9 \%)$ are marked in bold

5. We assume that $r=9 \%$. Measure $\alpha N P V_{j}$ is computed below for each project. Table 4 presents the values of that measure for $r \in[0.05,0.15]$.

$$
\begin{gathered}
\alpha N P V_{1}=-50-\frac{26.875}{1.09}+\frac{122.5}{(1.09)^{2}}+\frac{57.692}{(1.09)^{3}}=73.0, \\
\alpha N P V_{2}=62.19, \quad \alpha N P V_{3}=75.58
\end{gathered}
$$

6. $I_{j}^{*}=I_{3}$. The DM can select project $I_{3}\left(\alpha N P V_{3}>0\right)$.

According to the H+B rule for NPVU the DM should choose investment $I_{3}$ and steps 7-8 are not necessary. Nevertheless, thanks to the results gathered in Table 4 , it can be observed that for $r$ equal to at least $10 \%$, investment $I_{1}$ becomes the best. That is why, the DM ought to reconsider the level of the discount rate in order to make the final decision. A similar analysis for the coefficient of pessimism/optimism can be made. The data presented in Table 5 signify that for $\alpha<0.67$ investment $I_{1}$ becomes the best. Hence, before choosing project $I_{3}$, the DM should be really convinced that parameters $r$ and $\alpha$ have been estimated properly. We see that the sensitivity analysis may be an additional useful tool in the decision making process. It enables one to demonstrate how rankings change depending on the level of the discount rate, the coefficient of pessimism/optimism or the predicted future net cash flows. 
Table 5 Measures $\alpha N P V_{j}$ (in thousand dollars) for different values of $\alpha(r=9 \%)$. Source: prepared by the author

\begin{tabular}{llll}
\hline Coefficient of pessimism $\backslash$ investments & $\mathrm{I}_{1}$ & $\mathrm{I}_{2}$ & $\mathrm{I}_{3}$ \\
\hline 0.60 & 89.34 & 77.91 & 84.46 \\
0.65 & 81.54 & 70.51 & 80.18 \\
0.66 & 79.89 & 68.93 & 79.29 \\
0.67 & 78.21 & 67.30 & 78.38 \\
0.68 & 76.51 & 65.64 & 77.46 \\
0.69 & 74.77 & 63.94 & 76.53 \\
$\mathbf{0 . 7 0}$ & $\mathbf{7 3 . 0 0}$ & $\mathbf{6 2 . 1 9}$ & $\mathbf{7 5 . 5 8}$ \\
0.71 & 71.19 & 60.40 & 74.61 \\
0.72 & 69.35 & 58.57 & 73.63 \\
0.73 & 67.48 & 56.68 & 72.64 \\
0.74 & 65.57 & 54.75 & 71.63 \\
0.75 & 63.62 & 52.76 & 70.60 \\
0.80 & 53.25 & 41.99 & 65.21 \\
\hline
\end{tabular}

The values for the analyzed coefficient of optimism $(\alpha=0.7)$ are marked in bold

\section{Conclusions}

In this contribution we have described a possible modification of the original NPV in order to evaluate projects, and choose the best one, under uncertainty with unknown probabilities (probabilities are not treated as initial parameters of the decision problem). The proposed method allows one to apply scenario planning and to take into account the decision maker's attitude towards a given problem (measured by coefficients of pessimism and optimism). The new procedure can be used even in the case of asymmetric distributions of net cash flows at particular periods. The novel method does not require the estimation of probabilities, which is extremely desirable especially in the case of totally new decisions (projects) and for passive decision makers who do not intend to analyze each scenario, period and value very meticulously. Coefficients of optimism and pessimism are used to generate some probability-like quantities, which coincides with the theory of economics, according to which for the majority of uncertain problems, unknown objective or subjective probabilities may be replaced by other measures in order to quantify uncertainty. The approach presented in the paper has been called $\mathrm{H}+\mathrm{B}$ rule for NPVU since it is partially based on the original version of $\mathrm{H}+\mathrm{B}$ rule, which constitutes a hybrid of the Hurwicz and Bayes decision rules and which is designed for one-period decision problems. The modified version of $\mathrm{H}+\mathrm{B}$ rule enables one to consider multi-period scenario-based decision problems.

We are aware of the fact that the suggested method may lead only to partially rational decisions since, due to some unknown factors concerning the future, decision makers possess only "bounded rationality" and have to make decisions by "satisficing" or choosing what might not be optimal, but will make them happy enough (Frish and Baron 2006; Simon 1957, 1991). 
It is worth stressing that the H+B rule for NPVU may be applied rather on the assumption that the cash flow matrix is estimated by experts instead of the decision maker, since the values are objective ${ }^{2}$ and DM's attitude towards a given problem is considered by means of coefficients of pessimism/optimism. If the aforementioned matrix is estimated by the DM, there is a risk that his/her attitude will be considered twice: in the cash flow matrix and in the coefficients of pessimism/optimism, which may distort real DM's preferences (Gaspars-Wieloch 2015d).

Note that, as in the case of the Hurwicz rule, the suggested decision rule is a subjective procedure since the coefficient of optimism/pessimism is estimated subjectively.

As part of the concluding remarks, we ought to discuss the problem of group (collaborative) decision making because investment decisions are usually made collectively. Thus, particularly in corporate reality, the procedure described in the contribution cannot be directly used in the decision making process. Nevertheless, it can hold a consultative (advisory) function as the final collective decision may constitute, for instance, the most frequent response from among the results obtained separately for each decision maker on the basis of that decision rule. Additionally, using the $\mathrm{H}+\mathrm{B}$ rule for NPVU by particular members of a group facilitates the final collective choice of the best project since the original set of potential projects has the chance to be significantly reduced.

Another aspect, which needs to be mentioned in the paper, is related to the multistage character of the decision making process in the case of project selection. On the face of it, we could state that the $\mathrm{H}+\mathrm{B}$ rule for NPVU is designed only for one-stage decisions. However, it can be easily used in multi-stage group decisions and combined with the Delphi method, where it is believed that during consecutive rounds the range of the answers will decrease and the group will converge towards the "correct" answer. In the case of multi-stage individual decisions the use of the $\mathrm{H}+\mathrm{B}$ rule for NPVU could be also advantageous. First stages can, for example, concern situations where the investor is not able to determine a precise degree of optimism and, instead, he/she declares this parameter as an interval. Further stages concern a less "uncertain" uncertainty. Hence, the parameter can be estimated more precisely.

Owing to the fact that the project selection is a task requiring high responsibility, entailing expenditure and time-consuming execution, we would like to emphasize that the $\mathrm{H}+\mathrm{B}$ rule for NPVU cannot be applied rashly. We strongly recommend that decision makers support the procedure with the sensitivity analysis. Thus, before making the final decision, it is desirable to check how the NPVs and the project rankings change after a slight modification of the level of the optimism coefficient.

The $\mathrm{H}+\mathrm{B}$ rule for NPVU can be easily adjusted to further non-deterministic applications in areas such as the estimation of NPV with variable discount rates (for long-term investments), the NPV estimation with reinvested cash flows (Chandra 2009) and NPV

\footnotetext{
2 The more objective nature of scenario planning in the case of experts results from the fact that experts are better prepared to perform particular steps of that process. They are able (thanks to various methods such as brainstorming, 80:20 rule, Important Uncertainties Matrix) to determine the most important factors (variables) that will decide the nature of the future environment. They have sufficient skill to assess the impact of a given factor on the remaining ones. And finally, they can define the set of possible scenarios.
} 
assessment for make-to-order and make-to-stock manufacturing systems (Naim et al. 2007).

Acknowledgements This research is financed by the National Science Center in Poland (Project Registration Number: 2014/15/D/HS4/00771).

Open Access This article is distributed under the terms of the Creative Commons Attribution 4.0 International License (http://creativecommons.org/licenses/by/4.0/), which permits unrestricted use, distribution, and reproduction in any medium, provided you give appropriate credit to the original author(s) and the source, provide a link to the Creative Commons license, and indicate if changes were made.

\section{References}

Aven T (2016) Risk assessment and risk management: review of recent advances on their foundation. Eur J Oper Res 253:1-13. https://doi.org/10.1016/j.ejor.2015.12.023

Balen RM, Mens H-Z, Economides MJ (1988) Applications of the Net Present Value (NPV) in the optimization of hydraulic fractures. Society of Petroleum Engineers, Charleston. https://doi.org/10.2118/ 18541-MS

Basili M (2006) A rational decision rule with extreme events. Risk Anal 26:1721-1728. https://doi.org/10. $1111 /$ j.1539-6924.2006.00826.x

Basili M, Chateauneuf A, Fontini F (2008) Precautionary principle as a rule of choice with optimism on windfall gains and pessimism on catastrophic losses. Ecol Econ 67:485-491. https://doi.org/10.1016/ j.ecolecon.2007.12.030

Basili M, Chateauneuf A (2011) Extreme events and entropy: a multiple quantile utility model. Int J Approx Reason 52:1095-1102. https://doi.org/10.1016/j.ijar.2011.05.005

Beauchene D (2015) Solution concepts for games with ambiguous payoffs. Theory Decis. https://doi.org/ $10.1007 / \mathrm{s} 11238-015-9502-3$

Berk J, DeMarzo P, Stangeland D (2015) Corporate einance, 3rd edn. Pearson Canada, Toronto

Buser S (1986) LaPlace transforms as present value rules: a note. J Finance 41(1):243-247. https://doi.org/ 10.1111/j.1540-6261.1986.tb04502.x

Caplan B (2001) Probability, common sense, and realism: a reply to Hulsmann and Block. Q J Aust Econ 4(2):69-86

Carnap R (1950) Logical foundations of probability. University of Chicago Press, Chicago

Chandra P (2009) Projects: planning, analysis, selection, financing, implementation, and review, 7th edn. Tata McGraw-Hill, New Delhi

Chassein A, Goerigk M (2016) Minmax regret combinatorial optimization problems with ellipsoidal uncertainty sets. Eur J Oper Res. https://doi.org/10.1016/j.ejor.2016.10.055

Chiu CY, Park CS (1994) Fuzzy cash flow analysis using present worth criterion. Eng Econ 39(2):113-137. https://doi.org/10.1080/00137919408903117

Chronopoulos M, De Reyck B, Siddiqui A (2011) Optimal investment under operational flexibility, risk aversion, and uncertainty. Eur J Oper Res 213:221-237. https://doi.org/10.1016/j.ejor.2011.03.007

De Finetti B (1975) Theory of probability. A critical introductory treatment. Wiley, London

Dominiak C (2009) Multi-criteria decision aiding procedure under risk and uncertainty. In: Trzaskalik T (ed) Multiple criteria decision making. Publisher of The Karol Adamiecki University of Economics in Katowice, Katowice, pp 61-88

Dubois D, Prade H (2001) Possibility theory, probability theory and multiple-valued logics: a clarification. Ann Math Artif Intell 32:35-66. https://doi.org/10.1023/A:1016740830286

Dubois D, Prade H (2012) Gradualness, uncertainty and bipolarity: making sense of fuzzy sets. Fuzzy Sets Syst 192:3-24

Ellsberg D (2001) Risk, ambiguity and decision. Garland Publishing, New York

Etner J, Jeleva M, Tallon J-M (2012) Decision theory under ambiguity. J Econ Surv 26(2):234-270. https:// doi.org/10.1111/j.1467-6419.2010.00641.x

Fabozzi FJ, Fong GH (1994) Advanced fixed income portfolio management. Probus Publishing Company, Chicago 
Filho ACS, Vellasco M, Tanscheit R (2012) Modified Net Present Value under uncertainties: an approach based on fuzzy numbers and interval arithmetic. Advances in Computational Intelligence. Commun Comput Inf Sci 300:10-19. https://doi.org/10.1007/978-3-642-31724-8_2

Fishburn PC (1984) Foundations of risk measurement. I. Risk or probable loss. Manag Sci 30:396-406. https://doi.org/10.1287/mnsc.30.4.396

Fisher I (1907) The rate of interest. Macmillan, New York

Frechet M (1938) The diverse definitions of probability. Lecture at the fourth International Congress for the Unity of Science, Erkenntnis

Frish D, Baron J (2006) Ambiguity and rationality. J Behav Decis Mak 1(3):149-157. https://doi.org/10. 1002/bdm.3960010303

Gaspars-Wieloch H (2012) Ograniczona skuteczność metod optymalizacyjnych w rozwiązywaniu ekonomicznych problemów decyzyjnych (Limited efficiency of optimization methods in solving economic decision problems). Ekonomista 2012(3):303-324

Gaspars-Wieloch H (2013) On a decision rule supported by a forecasting stage based on the decision maker's risk aversion. In: Zadnik SL, Zerovnik J, Povh J, Drobne S, Lisec A (eds) Proceedings of the 12th international symposium of operational research. Lubjana, pp 53-59

Gaspars-Wieloch H (2014a). Propozycja hybrydy reguł Hurwicza i Bayesa w podejmowaniu decyzji w warunkach niepewności (A hybrid of the Hurwicz and Bayes rules in decision making under uncertainty). In: Trzaskalik T (ed) Modelowanie Preferencji a Ryzyko'14. Studia Ekonomiczne. Zeszyty Naukowe Uniwersytetu Ekonomicznego w Katowicach, vol 178. Katowice, pp 74-92

Gaspars-Wieloch H (2014) On a decision rule for mixed strategy searching under uncertainty on the basis of the coefficient of optimism. Procedia Soc Behav Sci. 110(2014):923-931. https://doi.org/10.1016/ j.sbspro.2013.12.938

Gaspars-Wieloch H (2014c) Modifications of the Hurwicz's decision rules. CEJOR 22(4):779-794. https:// doi.org/10.1007/s10100-013-0302-y

Gaspars-Wieloch H (2014d) Modification of the maximin joy criterion for decision making under uncertainty. Quant Methods Econ XV(2):84-93

Gaspars-Wieloch H (2015a) On a decision rule supported by a forecasting stage based on the decision maker's coefficient of optimism. CEJOR 23(3):579-594. https://doi.org/10.1007/s10100-014-03645

Gaspars-Wieloch H (2015) Modifications of the Omega ratio in decision making under uncertainty. Croat Oper Res Rev 6(1):181-194. https://doi.org/10.17535/crorr.2015.0015

Gaspars-Wieloch H (2015c) Innovative products and newsvendor problem under uncertainty without probabilities, In: Zadnik SL, Zerovnik J, Kljajic Borstnar M, Drobne S (eds) Proceedings of the 13th international symposium of operational research SOR'15. Slovenian Society INFORMATIKA, pp $343-350$

Gaspars-Wieloch H (2015d) On securities portfolio optimization, preferences, payoff matrix estimation and uncertain mixed decision making. Contemporary issues in business, management and education' 2015. https://doi.org/10.3846/cibme.2015.04

Gaspars-Wieloch H (2015e) A decision rule for uncertain multicriteria mixed decision making based on the coefficient of optimism. In: Multiple criteria decision making' 15, University of Economics in Katowice, pp 32-47

Gaspars-Wieloch H (2016a) Spare parts quantity problem, interval loss matrix and uncertainty with unknown probabilities. 28th European conference on operational research EURO'2016, 3-6 July 2016, p 330

Gaspars-Wieloch H (2016b) Ressource allocation under complete uncertainty-case of asymmetric payoffs. Organizacja i Zarządzanie 96:247-258

Gaspars-Wieloch H(2017a) Newsvendor problem under complete uncertainty: a case of innovative products. CEJOR 25(3):561-585. https://doi.org/10.1007/s10100-016-0458-3

Gaspars-Wieloch H (2017b) Innovative projects scheduling with scenario-based decision project graphs. In: Contemporary issues in business, management and education (2017) conference proceedings. VGTU Press. https://doi.org/10.3846/cbme.2017.078

Gaspars-Wieloch H (2017c) A decision rule based on goal programming and one-stage models for uncertain multi-criteria mixed decision making and games against nature. Croat Oper Res Rev 8(1):61-76

Gaspars-Wieloch H (2017d) The impact of the structure of the payoff matrix on the final decision made under uncertainty. Asia-Pac J Oper Res 34(6). https://doi.org/10.1142/S0217595917500373

Ghirardato P, Maccheroni F, Marinacci M (2004) Differentiating ambiguity and ambiguity attitude. J Econ Theory 118:133-173. https://doi.org/10.1016/j.jet.2003.12.004 
Gilboa I, Schmeidler D (1989) Maxmin expected utility with non-unique prior. J Math Econ 18:141-153. https://doi.org/10.1016/0304-4068(89)90018-9

Gilboa I (2009) Theory of decision under uncertainty. Cambridge University Press, Cambridge

Groenewald ME, Pretorius PD (2011) Comparison of decision making under uncertainty investment strategies with the money market. J Financ Stud Res. https://doi.org/10.5171/2011.373376

Grubbström R (1967) On the application of the Laplace transform to certain economic problems. Manag Sci 13:558-567. https://doi.org/10.1287/mnsc.13.7.558

Guney S, Newell BR (2015) Overcomming ambiguity aversion through experience. J Behavl Decis Mak 28(2):188-199. https://doi.org/10.1002/bdm.1840

Guo P (2011) One-shot decision theory. IEEE Trans Syst Man Cybern A 41(5):917-926. https://doi.org/ 10.1109/TSMCA.2010.2093891

Guo P, Ma X (2014) Newsvendor models for innovative products with one-shot decision theory. Eur J Oper Res 239:523-536. https://doi.org/10.1016/j.ejor.2014.05.028

Gutiérrez I (1989) Fuzzy numbers and Net Present Value. Scand J Manag 5:149-159. https://doi.org/10. 1016/0956-5221(89)90021-3

Halpern JY, Leung S (2014) Weighted sets of probabilities and minimax weighted expected regret: a new approach for representing uncertainty and making decisions. Theor Decis. https://doi.org/10.1007/ s11238-014-9471-y

Hau R, Pleskac TJ, Hertwig R (2009) Decisions from experience and statistical probabilities: Why they trigger different choices than a priori probabilities? J Behav Decis Mak. https://doi.org/10.1002/bdm. 665

Hayashi T (2008) Regret aversion and opportunity dependence. J Econ Theory 139(1):242-268. https:// doi.org/10.1016/j.jet.2007.07.001

Hurwicz L (1952) A criterion for decision making under uncertainty. Technical Report, 355. Cowles Commission

Ioan C, Ioan GA (2011) A method of choice of the best alternative in the multiple solutions case in the games theory. J Account Manag 1(1):5-8

Kaplan S, Barish NN (1967) Decision-making allowing for uncertainty of future investment opportunities. Manag Sci 13(10):569-577. https://doi.org/10.1287/mnsc.13.10.B569

Knight F (1921) Risk, uncertainty, profit. Hart. Schaffner \& Marx, Houghton Mifflin Co., Boston

Kofler E, Zweifel P (1993) One-shot decisions under linear partial information. Theor Decis 34:1-20. https://doi.org/10.1007/BF01076102

Kolmogorov AN (1933) Grundbegriffe der Wahrscheinlichkeitsrechnung. Julius Springer, Berlin

Lin GCI, Nagalingam SV (2000) CIM justification and optimisation. Taylor \& Francis, London

Liu B (2007) Uncertainty theory, 2nd edn. Springer, Berlin

Liu B (2009) Some research problems in uncertainty theory. J Uncertain Syst 3(1):3-10

Marinacci M (2002) Probabilistic sophistication and multiple priors. Econometrica 70:755-764. https:// doi.org/10.1111/1468-0262.00303

McClure KG, Girma PB (2004) Modified Net Present Value (MNPV): a new technique for capital budgeting. Zagreb Int Rev Econ Bus 7:67-82

Naim MM, Wikner J, Grubbström RW (2007) A Net Present Value assessment of make-to-order and make-to-stock manufacturing systems. Omega 35(5):524-532. https://doi.org/10.1016/j.omega.2005. 09.006

Nakamura K (1986) Preference relations on a set of fuzzy utilities as a basis for decision making. Fuzzy Sets Syst 20:147-162. https://doi.org/10.1016/0165-0114(86)90074-6

Ogryczak W, Sliwinski T (2009) On efficient WOWA optimization for decision support under risk. Int J Approx Reason 50:915-928. https://doi.org/10.1016/j.ijar.2009.02.010

Perez DE, Hernandez JG, Garcia MJ, Hernandez GJ (2015) Hurwicz method modified and the Amplitude Model (TAM). In: Delener et al (ed) GBATA2015 Reading book. GBATA, USA, pp 559-566

Piasecki K (1990) Decyzje i wiarygodne prognozy (Decision reliable forecasts). Akademia Ekonomiczna w Poznaniu, Poznań

Piasecki K, Ronka-Chmielowiec W (2011) Matematyka finansowa (Financial mathematics). Wydawnictwo C.H.-Beck, Warszawa

Piasecki K (2016) Intuicyjne zbiory rozmyte jako narzędzie finansów behawioralnych. (edu-Libri)

Piegat A (2010) Uncertainty of probability. Workshop on Intuitionistic Fuzzy Sets and Generalized Nets

Pomerol JC (2001) Scenario development and practical decision making under uncertainty. Decis Support Syst 31(2):197-204. https://doi.org/10.1016/S0167-9236(00)00131-7 
Popper K (1959) The propensity interpretation of probability. Br J Philos Sci 10(37):25-42

Render B, Stair R, Hanna M (2006) Quantitative analysis for management. Pearson Prentice Hall, Upper Saddle River

Roszkowska E, Wachowicz T (2015) Inaccuracy in defining preferences by the Electronic Negotiation System Users. Lect Notes Bus Inf Process 218:131-143. https://doi.org/10.1007/978-3-319-195155_11

Savage L (1961) The foundations of statistics reconsidered. Studies in Subjective Probability. Wiley, New York, pp 173-188

Schmeidler D (1986) Integral representation without additivity. Proc Am Math Soc 97:255-261. https:// doi.org/10.1090/S0002-9939-1986-0835875-8

Shafer G (1976) A mathematical theory of evidence. Princeton University Press, Princeton

Sentz K, Ferson S (2002) Combination of evidence in Dempster-Shafer theory. Sandia Report SAND20020835, April 2002, Albuquerque, NM

Sikora W (ed) (2008) Badania operacyjne (Operations research). Polskie Wydawnictwo Ekonomiczne, Warsaw

Simon H (1957) A behavioral model of rational choice. In models of man, social and rational: mathematical essays on rational human behavior in a social setting. Wiley, New York

Simon H (1991) Bounded rationality and organizational learning. Organ Sci 2(1):125-134. https://doi.org/ 10.1287/orsc. 2.1 .125

Tannert C, Elvers HD, Jandrig B (2007) The ethics of uncertainty. In the light of possible dangers, research becomes a moral duty. EMBO Rep 8(10):892-896

Trzaskalik T (2008) Wprowadzenie do badań operacyjnych z komputerem (Introduction to operations research with computer), 2nd edn. Polskie Wydawnictwo Ekonomiczne, Warsaw

Tversky A, Kahneman D (1992) Advances in prospect theory: cumulative representation of uncertainty. J Risk Uncertain 5:297-323. https://doi.org/10.1007/BF00122574

Van der Heijden K (1996) Scenarios: the art of strategic conversation. Wiley, Chichester

Van Lambalgen M (1996) Randomness and foundations of probability: von Mises' axiomatization of random sequences. Probability, statistics and game theory, papers in honor of David Blackwell, Institute for Mathematical Statistics

Von Mises L (1949) Human action: a treatise on economics. Yale University Press, New Haven

von Neumann J, Morgenstern O (1994) Theory of games and economic behavior. Princeton University Press, Princeton

Von Mises R (1957) Probability, statistics and truth. The Macmillan Company, New York

Wald A (1950) Statistical decision functions. Wiley, New York

Walley P (1991) Statistical reasoning with imprecise probabilities. Chapman and Hall, London

Waters D (2011) Supply chain risk management. Vulnerability and resilience in logistics. Kogan Page, London

Weber M (1997) Decision making with incomplete information. Eur J Oper Res 28:44-57. https://doi.org/ 10.1016/0377-2217(87)90168-8

Zadeh L (1978) Fuzzy sets as the basis for a theory of possibility. Fuzzy Sets Syst 1:3-28. https://doi.org/ 10.1016/0165-0114(78)90029-5

Zio E, Pedroni N (2013) Methods for representing uncertainty. A literature review. Apports de la recherche 2013-3. Risk Analysis. Les cahiers de la securite industrielle. FONCSI 